\title{
Experimental Survey on Dry Asphalt Rubber Concrete for Sub-ballast Layers
}

\author{
Gaetano Di Mino and Ciro Maurizio Di Liberto \\ Department of Civil, Environmental and Aerospace Engineering, Faculty of Engineering, University of Palermo, Palermo 90128 , \\ Italy
}

\begin{abstract}
This paper presents the results of an experimental survey on the potential application of DARC (dry asphalt rubber concrete) in rail superstructure, within sub-ballast layers by measuring its damping and mechanical properties. Based on the environmental friendly point of view the DARC has the significant advantage as the backfill material of sub-ballast layer because the rubber comes from the waste tires of truck and its usage can results a significant recycling of non-biodegradable wastes. After a preliminary mix-design of several DARCs, with different rubber content that confirmed by using the Marshall test, the stiffness modulus and damping ratio both of a standard bituminous mixture and of dry asphalt rubber concrete with a rubber content equal to $1.5 \%$ were determined using the four points bending device. The experimental results were compared and a numerical analysis by means of a 2D lumped mass model was developed in order to evaluate the different performance within the rail superstructure in terms both of the deflection and of the pressure on sub-grade. Both the results on the mechanical and dissipative properties of the DARC and the mechanical behavior of the correlate rail superstructure encourage the authors to continue the research on the application of such material for sub-ballast layers.
\end{abstract}

Key words: Damping, stiffness modulus, dry asphalt rubber concrete, sub-ballast layers.

\section{Introduction}

The improvement of the mechanical performances of the ballasted rail track by means of strengthening the sub-ballast layer has been acknowledged for a long time [1-3].

Generally, such improvement is by improving the fatigue resistance capability of the sub-ballast, hence, the whole rail track condition can be updated. In fact, the tensile stress at the bottom of the ballasted rail track (i.e., at the bottom of the sub-ballast) can be decreased.

Therefore, sub-ballast layer have been complied by many railway companies and authorities in many European countries and worldwide [4].

The first recorded usage can be found back to the 1960s in the USA, some experimental applications

Corresponding author: Gaetano Di Mino, associate professor, research fields: road pavement design and management, innovative pavement materials, porous asphalt concrete and railway engineering. E-mail: gaetano.dimino@unipa.it. occurred [5] by that time, but the systematic use of the asphalt sub-ballast in substitution of the unbound sub-ballast or of the geotextile layer just occurred since the 1980s both for the rehabilitation of the existing rail track and for the new rail track construction [6-7].

Since the 1970s, Japanese railway started to use the sub-ballast concept both for their Shinkansen high-speed system and the conventional lines [8].

Since the 1990s, in Italy, all the ballasted rail track lines have installed the asphaltic sub-ballast layer with the thickness of $120 \mathrm{~mm}$ [9]. Moreover, some experimental tests have been done by RFI (Rete Ferroviaria Italiana - Railway Italian Network) and the results are very positive and it is also been found that the asphaltic sub-ballast layer also can reduce the ground borne vibrations [10].

Recent studies have demonstrated that the asphalt rubber sub-ballast layer can provide significant impact attenuation to the ground borne vibrations than the traditional sub-ballast materials. The asphalt rubber 
can be utilized by two different ways: the dry process and the wet process [11-13]. Moreover, the greater quantity of the rubber involved by the dry process and its influence on the mechanical parameters of the bituminous mixtures seem to give higher damping capability to the sub-ballast [14].

Some experimental researches showed that the dynamic and damping performance are better if the rubber content is higher [14-16].

Zhong et al. [16], through the resonant column and cyclic triaxial tests, determined the shear modulus and the damping ratio of the rubberized asphalt produced by means of the wet process, varying the type and the content of the rubber.

They demonstrated that a rubber content equal to $20 \%$ of weight of the binder produces an average value of the damping ratio equal to 0.095 versus the 0.055 of a normal bituminous mixture.

Furthermore, the authors studied the influence of both the confining pressure and cyclic shear strains on the stiffness and the damping properties of the materials.

For the numerical studies, D'Andrea et al. [14] using the 2D and 3D FEM (finite element method) models, demonstrated that the sub-ballast layer with dry rubber asphalt (thickness equal to $120 \mathrm{~mm}$ and rubber content equal to $5 \%$ by weight of the aggregates) produces a greater reduction of the RMS (root mean square) value of the acceleration equal to $4 \mathrm{~dB}$, over the $50-125 \mathrm{~Hz}$ frequency range, in comparison with the asphalt sub-ballast.

But for thickness equal to $200 \mathrm{~mm}$ the asphalt sub-ballast has better properties concerning damping ratio than the one with dry rubber asphalt over $10-40$ $\mathrm{Hz}$ frequency range.

Three different sub-ballast layers with the same thickness, equal to 200, made up respectively of concrete, asphalt and rubber asphalt were compared by Wang et al. [17]. These researchers by means of a 3D FEM model calculated the RMS and the peak values of acceleration in comparison with a ballasted rail track without sub-ballast in several points at different distances from the rail track.

The best performance in terms of reduction of ground borne vibrations was reached by rubber asphalt sub-ballast which produced, at $20 \mathrm{~m}$ from the rail track, both a reduction of the RMS (47.3\%) and the peak values of acceleration (50.3\%). In this study, it came out a considerable influence both of the sub-ballast's thickness and the velocity of the train on the efficiency of the sub-ballast against the ground borne vibrations.

In Italy, in light of the environmental issues, a law D.M. 203/2003 established that the use of the recycled rubber from the waste tires has to be increased both in the road infrastructures and in the railways [18].

However, the applications of the rubber asphalt via dry process for sub-ballast are very few because both its stiffness and fatigue behavior are not investigated enough.

In this paper, through an experimental investigation carried out in the Laboratory of the Road Materials of Department of Civil, Environmental and Aerospace Engineering at the University of Palermo, the authors have focused on the mechanical properties of the DARC (Dry Asphalt Rubber Concrete) as vibration attenuation material for sub-ballast layer.

For this purpose, two materials were analyzed and compared: the first was a bituminous mixture according to RFI standards; the second was a DARC with a content rubber equal to $1.5 \%$ by weight of the aggregates.

The test procedures were conducted by means of the four bending points (4PB-PR) apparatus and the Marshall test.

The use of the materials was finally evaluated by means of a 2D lumped masses model of the rail track-train system.

\section{Laboratory Tests}

The objective of the experimental study is to determine the influence of the rubber content, of the load frequency and of the temperature on the 
mechanical and dissipative properties of the materials for the sub-ballast.

The stiffness and the damping ratio of each material were determined using the four bending points test on prismatic specimens (4BP-PR) according to the UNI EN 12697-26 2004 [19], at the temperatures of $10^{\circ} \mathrm{C}$, $17^{\circ} \mathrm{C}$ and $25^{\circ} \mathrm{C}$.

The recycled crumb rubber comes from the waste tires of truck and so it can be considered as natural rubber which is more suitable to the mixing with the asphalt concrete.

\subsection{Materials}

The limestone aggregates here used for the mixtures are commonly adopted in Western Sicily. The Table 1 reports the properties of the aggregates.

It was considered the gradation master band of the RFI standards and the average gradation was selected as showed in Fig. 1.

The Table 2 shows the properties of the binder.

The ambient crumb rubbers which dimensions vary within $0.425-4.76 \mathrm{~mm}$ were used.

Table 1 Physical properties of the aggregates.

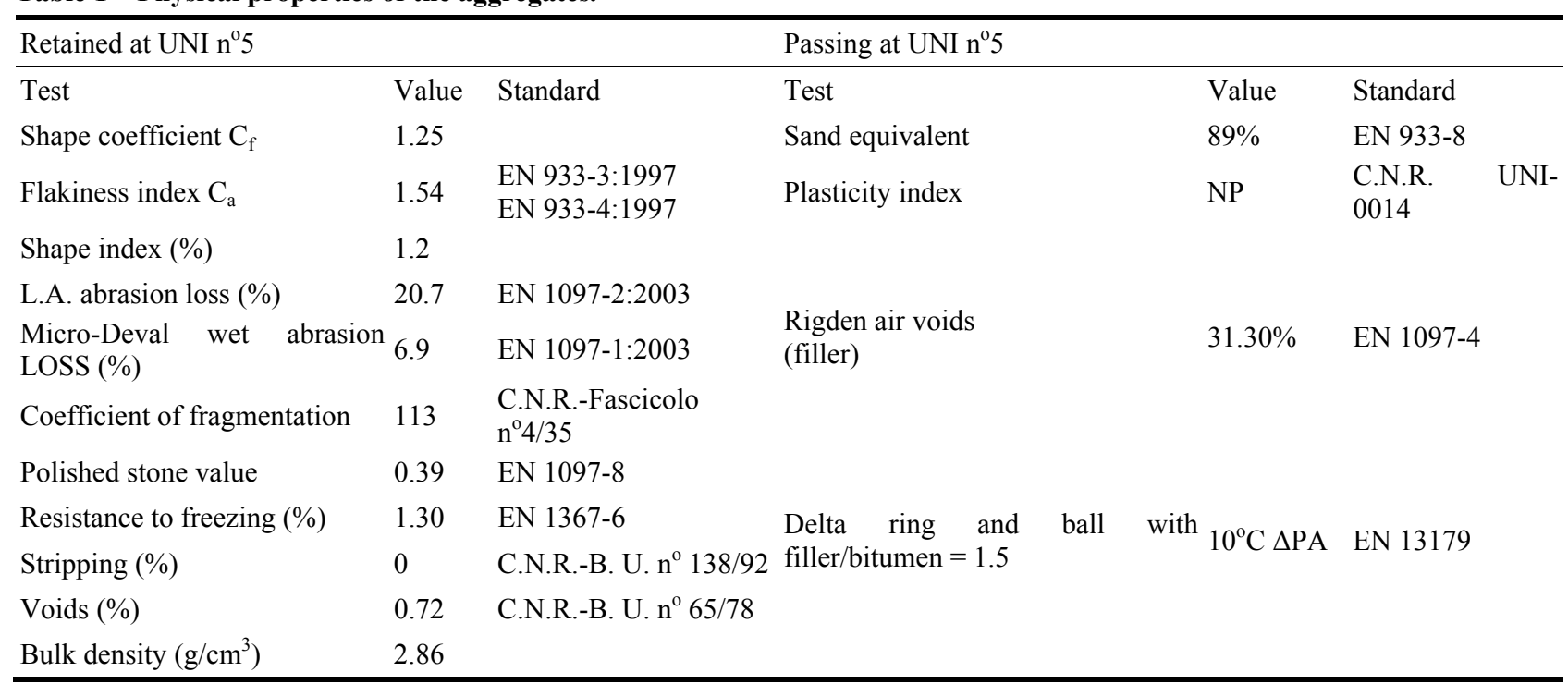

HMA-RFI gradation

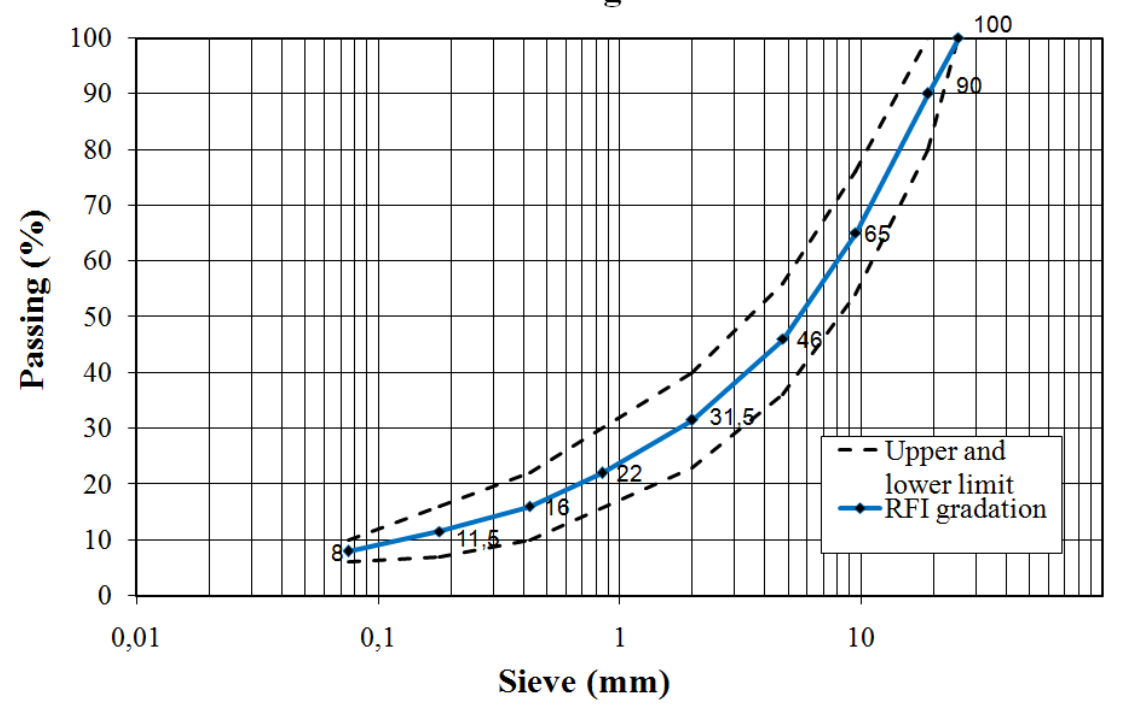

Fig. 1 RFI master band gradation. 
The Fig. 2 shows the gradation of the rubber which has a bulk gravity value equal to $1.15 \mathrm{gr} / \mathrm{cm}^{3}$.

As proposed by Ref. [12], the Dry Asphalt Rubber Concrete was obtained by means of the substitution of the limestone aggregates with the crumb rubber in volumetric proportion.

\subsection{Mix Design Method}

The preliminary mix design was carried out according to the Marshall test [20] using about 100 specimens in the Laboratory of the Road Materials of Department of Civil, Environmental and Aerospace Engineering at the University of Palermo.

Five DARC mixtures with different rubber content and one traditional mixture were designed.

Only the bituminous mixture without rubber is consistent to Italian specifications ( $\geqq 2.5 \mathrm{kN} / \mathrm{mm}$ ) in terms of the stiffness over the nearly entire range of the binder content (Fig. 3).

In relation to the DARCs in seldom cases and for small rubber content (1\%-2\%) the Marshall test gives consistent values to Italian specifications in terms of the stiffness (Fig. 3).

On the basis of the mix design these conclusions can be drawn:

- Only the bituminous mixture without rubber can be considered acceptable for the limits of the Italian specification according to the stiffness over the nearly entire range of the binder content;

- Only the DARC1.0 and the DARC2.0 could be considered acceptable for the above mentioned limits but for too low binder content.

Table 2 Physical and rheological properties of the binder.

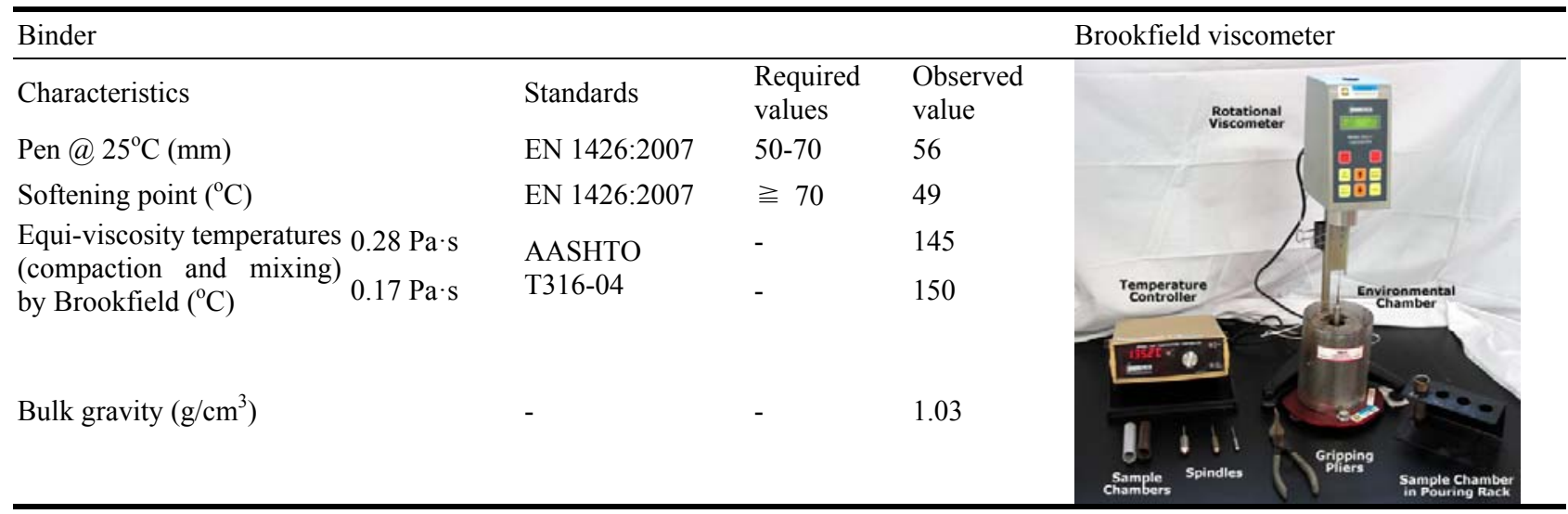
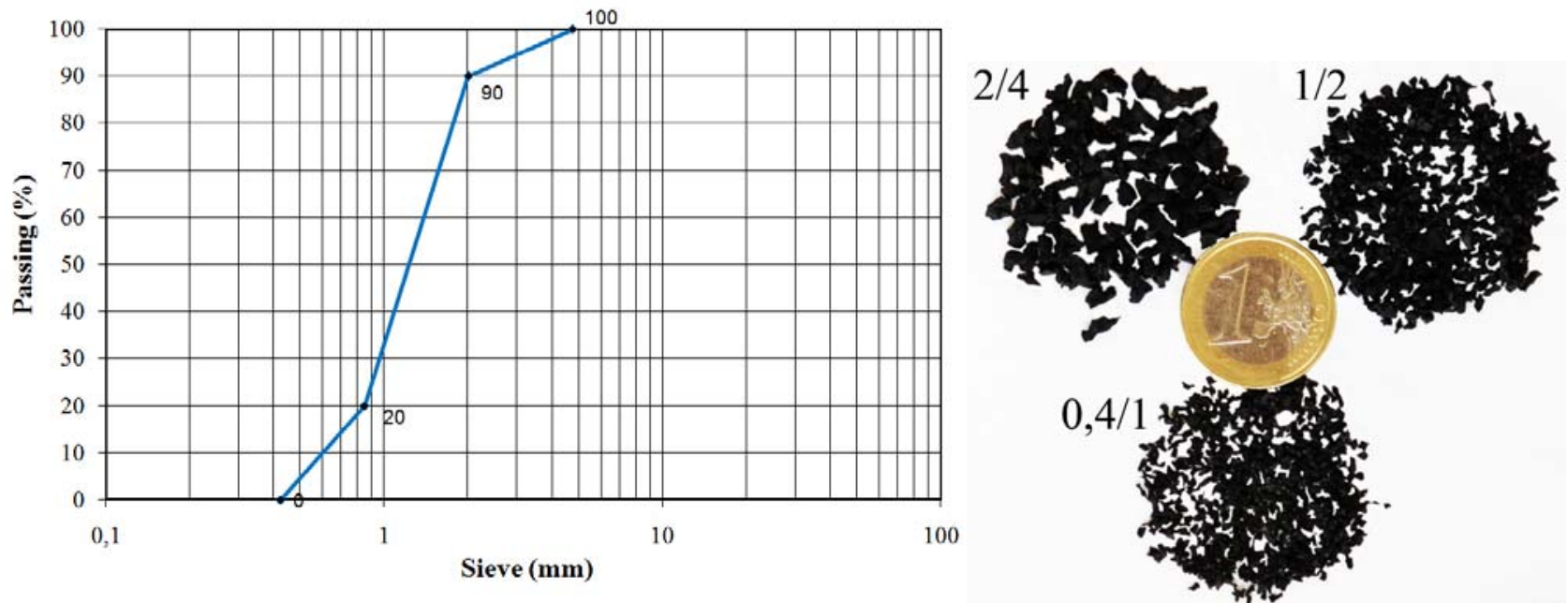

Fig. 2 Rubber gradation. 

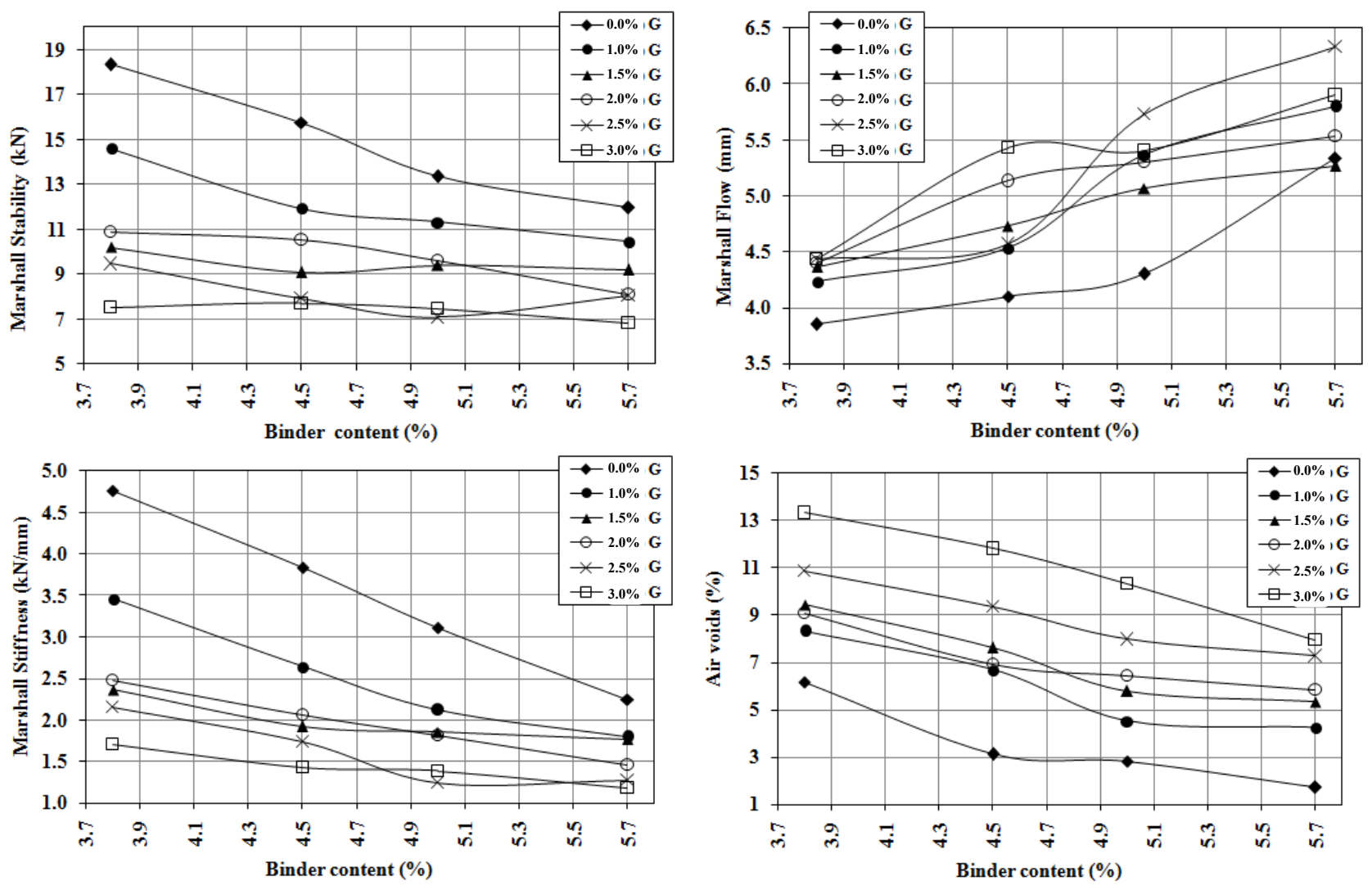

Fig. 3 Marshall test parameters.

However, it has to be considered that this mix-design procedure is absolutely reliable within the field of the typical bituminous mixtures while such procedure can only give some indications about new materials such as the DARC: in fact the Italian specifications do not take into account other materials except the typical bituminous mixtures.

In light of these reasons it was selected the intermediate DARC between DARC 1.0 and DARC2.0.

\subsection{Test Procedure}

The four point bending test on prismatic specimens [19] was carried out in order to evaluate the mechanical behavior and the damping property of the two bituminous mixtures.

The small HMA beams $(380 \times 50 \times 63 \mathrm{~mm})$ are made and placed in a 4-point loading machine, which subjects the beam to a repeated load. Tests can be run at a constant strain level or at a constant stress level in

order to determine the complex modulus and the damping ratio of the bituminous mixture. Fig. 4 shows the major test equipment.

The test is generally carried out by keeping constant the frequency and the temperature.

The specimens were obtained through the cut of a several HMA and DARC slabs manufactured in laboratory under static compaction.

In Table 3 there are reported the main volumetric parameters of the two materials.

The test ran at the temperature of $10^{\circ} \mathrm{C}, 17^{\circ} \mathrm{C}$ and $25^{\circ} \mathrm{C}$ which can be considered typical values of the average seasonal temperature in the South of the Italy [21]. The loading frequencies set $0.1 \mathrm{~Hz}, 0.5 \mathrm{~Hz}, 1 \mathrm{~Hz}$, $2 \mathrm{~Hz}, 5 \mathrm{~Hz}, 10 \mathrm{~Hz}, 15 \mathrm{~Hz}$ and $20 \mathrm{~Hz}$ was selected.

In order to reproduce a representative levels of the strain and the stress caused by train on the sub-ballast [2] all the tests were carried out by applying a strain wave shape with a peak to peak amplitude equal to 30 $\mu \mathrm{m} / \mathrm{m}$ and a mean strain level equal to $15 \mu \mathrm{m} / \mathrm{m}$. 

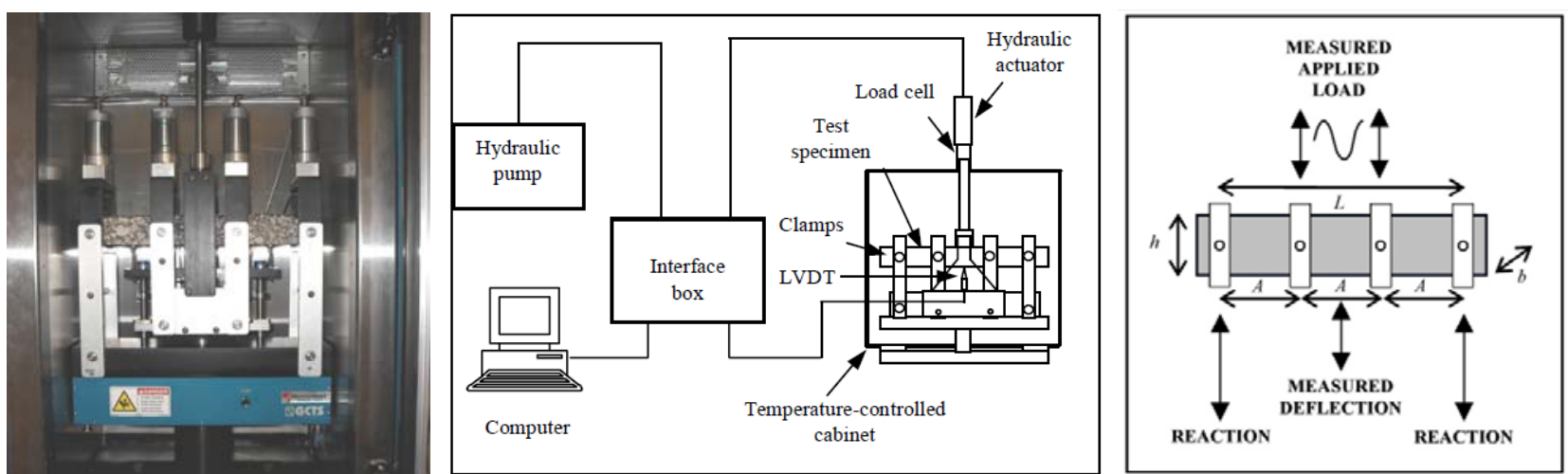

Fig. 4 4PB-PR apparatus, experimental setup and load pattern.

Table 3 Volumetric parameters.

\begin{tabular}{lllll}
\hline Mix identification & Binder content (\%) & Rubber content (\%) & Air voids percent (\%) & Specific Gravity $\left(\mathrm{kg} / \mathrm{m}^{3}\right)$ \\
\hline HMA-RFI & 4.5 & 0 & 4.4 & 2,534 \\
DARC1.5 & 5.5 & 1.5 & 6.6 & 2,375 \\
\hline
\end{tabular}

\subsubsection{Stiffness Modulus}

The complex modulus of a linear visco-elastic material, which is subjected to a cyclic sinusoidal load, is given by the ratio stress/strain according to the following relation, both the stress and the strain depend on the application time of the load.

$$
E^{*}=\frac{\sigma(t)}{\varepsilon(t)}=\frac{\sigma_{o} \cdot \operatorname{sen}(\omega \cdot t)}{\varepsilon_{o} \cdot \operatorname{sen}(\omega \cdot t-\phi)}=\frac{\sigma_{o}}{\varepsilon_{o}} \cdot e^{i \cdot \phi}=\left|E^{*}\right| \cdot e^{i \cdot \phi}
$$

In this relation, $\left|E^{*}\right|$ is called stiffness modulus, $\sigma_{o}$ and $\varepsilon_{o}$ are respectively the peak to peak amplitude of the stress and of the strain, $\omega=2 \pi f$, where, $f$ is the load frequency and $\omega$ is called pulsation, $\phi$ is the phase angle which represents the lag between the stress and the strain.

In Fig. 5 are reported the isothermal curves of the stiffness modulus of the considered materials.

The experimental results matched those of the other similar researches: in fact for given frequency the stiffness modulus increases if the temperature decreases while, for given temperature, it can be seen that the stiffness modulus increases if the frequency increases.

Furthermore, the experimental results showed that the DARC stiffness modulus is lower than the HMA-RFI one for each combination of temperature and frequency.
Within the frequency range $(2 \mathrm{~Hz}, 20 \mathrm{~Hz})$ which is particularly relevant in railway field, the value of DARC stiffness modulus is about a half of the HMA-RFI one. However the DARC stiffness modulus may be still considered suitable for the sub-ballast.

The master curves of the two materials at the temperature of $17^{\circ} \mathrm{C}$ are reported in Fig. 6.

\subsubsection{Damping Ratio}

The damping ratio represents a relevant measure of the dissipation property of a material.

Through the 4PB-PR test the damping ratio $\xi$ was determined.

In relation to the linear viscosity model of a system with one freedom degree, the damping ratio is calculated by the formula: $\xi=C / C_{c r}$, where, $C$ is the damping proportionality constant between the viscous forces and the oscillation velocities, while $C_{c r}$ is the critical damping or in other words the value for which there are not oscillatory free vibrations.

Further the damping ratio can be also calculated by the following equation [22]:

$$
\xi=\frac{\eta}{2}=\frac{1}{2} \frac{E_{2}}{E_{1}},
$$

where, $\eta$ is the loss factor, $E_{1}$ and $E_{2}$ are respectively the real component and imaginary component of the complex modulus $E^{*}$. 
(a)

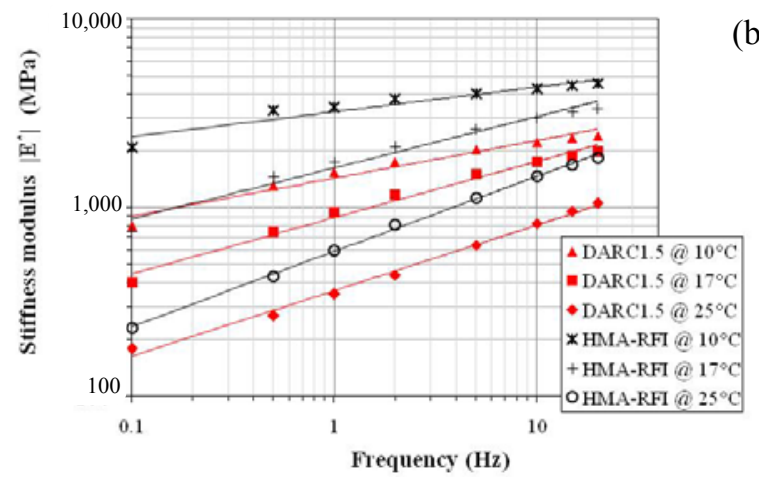

(b)

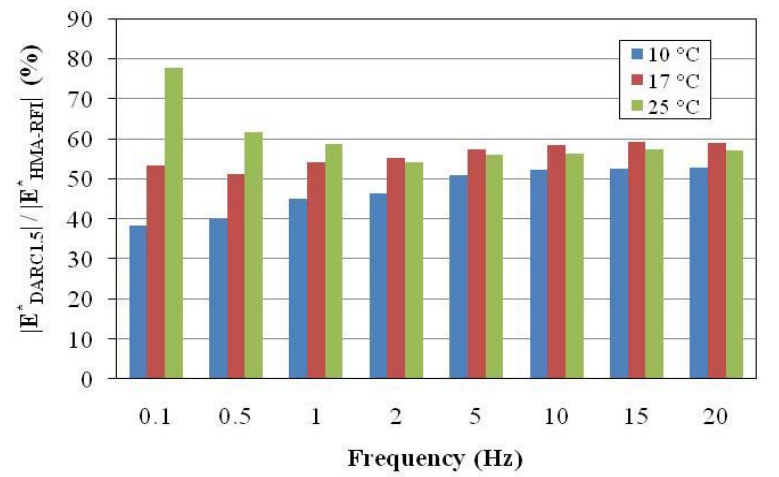

Fig. 5 the isothermal curves of the stiffness modulus of the considered materials: (a) Isothermal curves of the stiffness modulus @ $\boldsymbol{\varepsilon}_{\boldsymbol{o}}=\mathbf{3 0} \boldsymbol{\mu \mathbf { m }} / \mathbf{m}$; (b) $\frac{\left|E_{H M A-R F I}^{*}\right|}{\left|E_{D A R C 1.5}^{*}\right|} \times 100$ versus frequency.

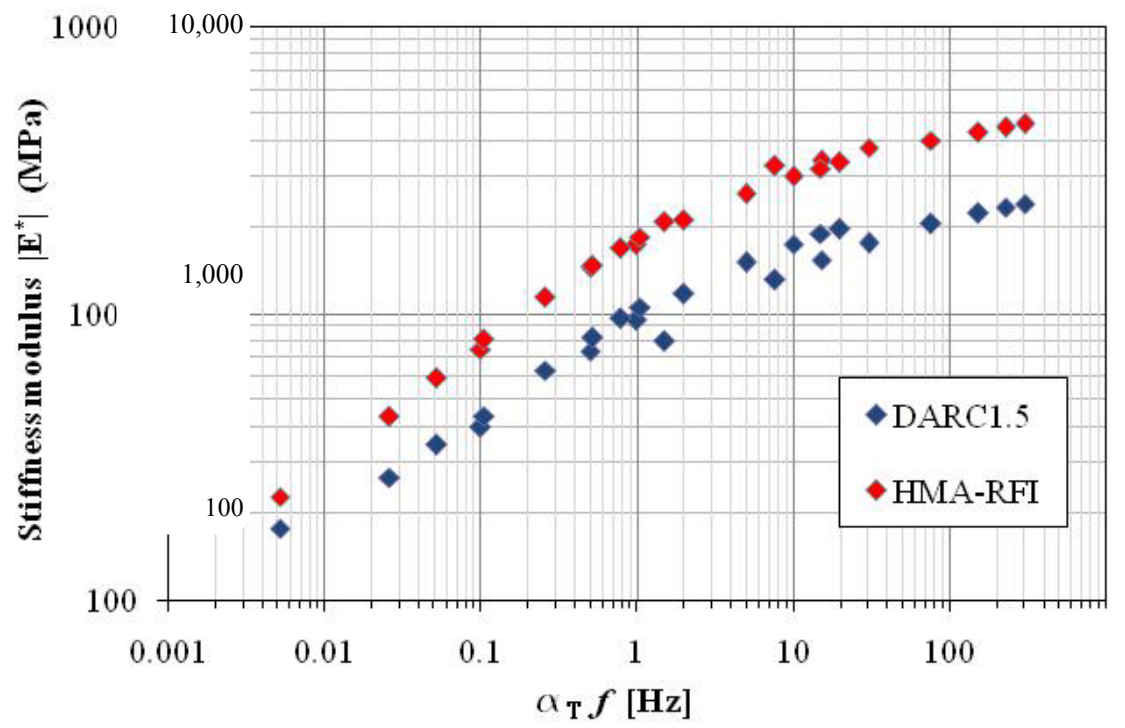

Fig. 6 Master Curves $\left(T_{s}=290^{\circ} \mathrm{K}, \Delta H=265 \mathrm{KJ} /{ }^{\circ} \mathrm{K}\right.$ mole $)$.

The damping ratio was determined using the latter equation by means of the phase angle $\phi=$ $\arctan \left(\mathrm{E}_{2} / \mathrm{E}_{1}\right)$.

In Fig. 7a, the isothermal curves of the damping ratio at the temperatures of 10,17 and $24^{\circ} \mathrm{C}$ within the range frequency $0.1-20 \mathrm{~Hz}$, for a strain level $\varepsilon_{o}$ equal to 30 $\mu \mathrm{m} / \mathrm{m}$ are reported.

The results put in evidence that the value of the damping ratio depends on both the temperature and the frequency because the dissipative properties of the material increased in relation to an increase of the temperature and/or to a decrease of the frequency. Such behavior depends on the rheological behavior of the binder for which, as known, the viscous properties are enhanced by an increase of the temperature and/or to a decrease of the frequency.

As shown in Fig. $7 \mathrm{~b}$ the DARC $1.5 \xi$ value at $17^{\circ} \mathrm{C}$ and $25^{\circ} \mathrm{C}$ was higher $(5 \%-27 \%)$ than the HMA-RFI one. The main increases $(40 \%-127 \%)$ of the damping ratio were reached at $10^{\circ} \mathrm{C}$.

This phenomenon can be explained considering that the rubber does not show a considerable variation of the dissipative properties in relation to the variation of the temperature and of the frequency.

Therefore, at the low temperatures the rubber just gives the main contribution to the damping properties of the asphalt mixtures. 
(a)

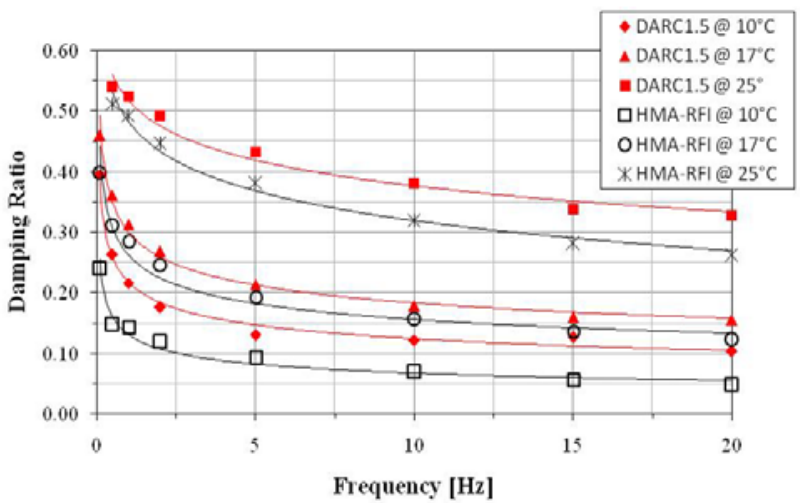

(b)

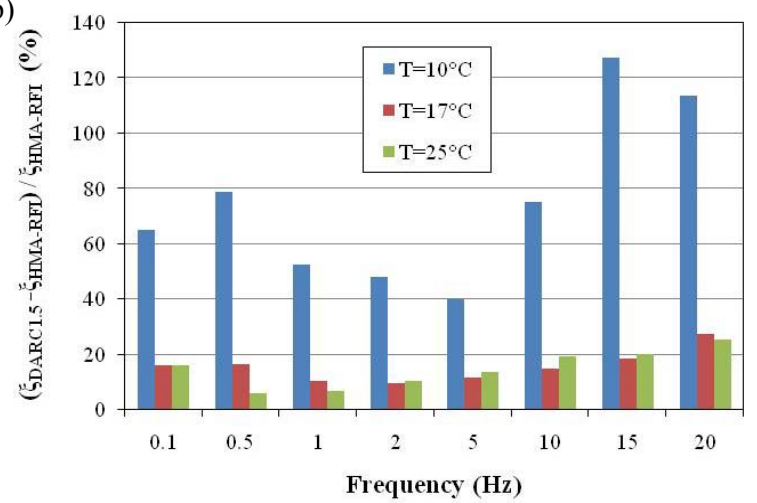

Fig. 7 The damping ratio and frequency: (a) Isothermal curves of the damping ratio @ $\varepsilon_{o}=30 \mu m / m ;$ (b) $\frac{\xi_{D A R C 1.5}-\xi_{H M A-R F I}}{\xi_{H M A-R F I}} \times 100$ versus frequency.

\section{Numerical Analysis}

In order to analyze the performance of the dry asphalt rubber within a sub-ballast layer a numerical analysis was carried out by means of a 2D lumped masses model of the rail track system with four levels of elasticity.

The mechanical performances of three rail tracks (the first with a sub-ballast made up of DARC1.5, the second with a sub-ballast made up of HMA-RFI and the third with an over compacted layer under the ballast) were evaluated and compared. The thickness of the two sub-ballasts is equal to $120 \mathrm{~mm}$ (Fig. 8a) while the thickness of the over-compacted layer is equal to $30 \mathrm{~cm}$ (Fig. 8b).

Besides it was considered a soft subgrade with a Young's modulus $E_{s g}$ equal to $20 \mathrm{MPa}$ in order to evaluate the mechanical behavior of the each rail track under restrictive conditions.

\subsection{Lumped Mass Models}

The model of the ballasted rail track with asphalt sub-ballast and the other are respectively showed in Fig. $9 \mathrm{a}$ and $9 \mathrm{~b}$.

The rail, modeled as a viscoelastic continuous beam, is considered connected, with periodicity equal to the distance between the sleepers, to a series of spring-damping elements $\left(K_{p}, C_{p}\right)$ which reproduce the dynamic behavior of the fastening system.
These elements represent the first level of elasticity and are connected to the concentrated masses $M_{s}$ representing the vertical inertia of the sleepers. The inertial behavior of the ballast portions beneath each sleeper is modeled with the masses $M_{b}$, consequently the second level of elasticity is obtained by interjecting a series of spring-damping elements $\left(K_{b}-C_{b}\right)$ arranged vertically between the concentrated masses $M_{s}$ and $M_{b}$.

Also, in order to simulate the shear behavior of the ballast, each mass $M_{b}$ is connected elastically $\left(K_{w}-C_{w}\right)$ to the next.

The third level of elasticity is made up of the elements $K_{f} C_{f}$, which are attached above to the ballast elements and below to a rigid boundary, modeling the mechanical behavior of the subgrade.

The bending behavior of the sub-ballast is modeled by placing a viscoelastic continuous beam which is connected to the upper levels by means of spring-damping elements $\left(K_{s}-C_{s}\right)$ which take in account the vertical displacement of the layer.

The fourth level of elasticity is modeled by interjecting a series of spring-damping elements $\left(K_{f} C_{f}\right)$ arranged vertically between the viscoelastic beam and a rigid base; it reproduces the viscoelastic behavior of the subgrade.

The considered load consists of a single vehicle which was modeled with a lumped mass system with 10 degrees of freedom [23]. 
(a)

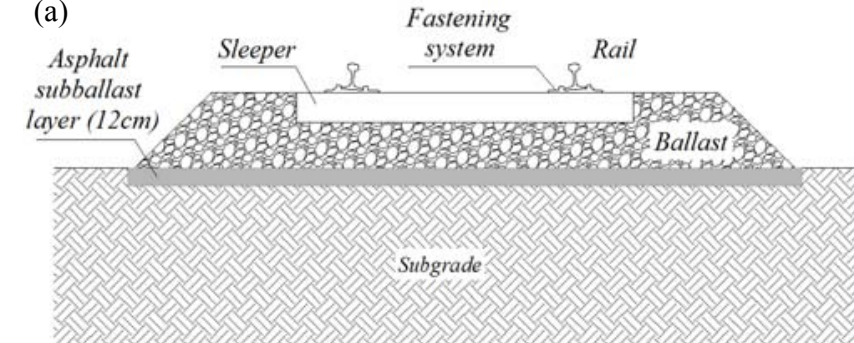

Fig. 8 Typical italian ballasted rail track (B category): (a) with asphalt sub-ballast; (b) with over compacted layer.

(a)

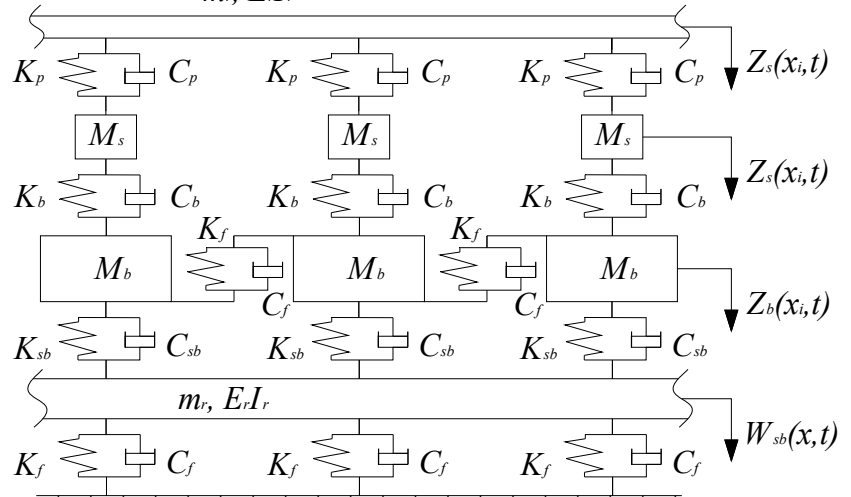

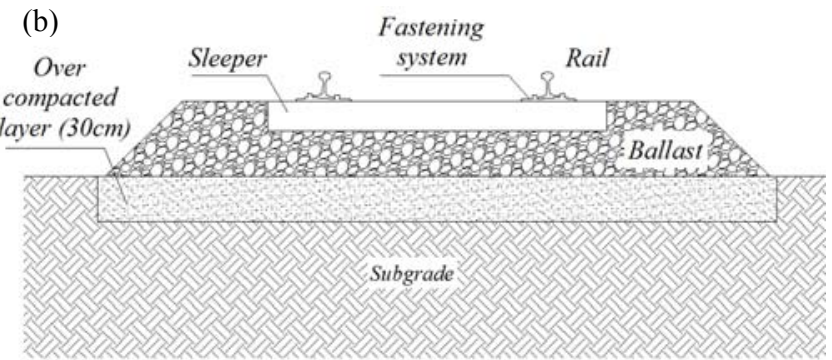

(b)

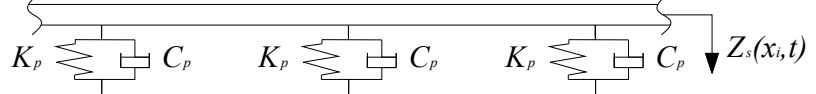
$K_{b} \sum_{5} C_{b} \quad K_{b} \sum_{M_{f}} C_{b} \quad K_{b} \sum_{I_{f}} C_{b} \nabla Z_{s}\left(x_{i}, t\right)$

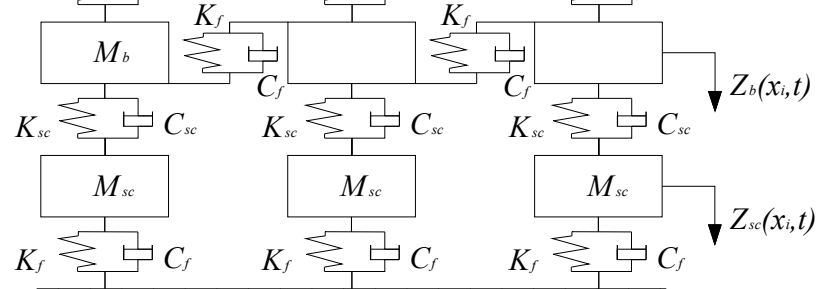

Fig. 9 Typical Italian ballasted rail track (B category): (a) with asphalt sub-ballast; (b) with over compacted layer.

The response of the rail track system is obtained through the implicit step by step integration of the equilibrium equations both of the vehicle and the rail track [24-25].

In relation to the model of the Fig. $9 \mathrm{~b}$ the over-compacted layer does not show a bending behavior.

In light of this the third level of elasticity is represented by a discrete masses $\left(M_{s b}\right)$, springs $\left(K_{s b}\right)$ and dampers $\left(C_{s b}\right)$.

\subsection{Modeling Data}

It was considered a rail UNI60 and concrete sleepers with distance between the sleepers equal to $650 \mathrm{~mm}$.

In Table 4 the modelling data are reported. For the sub-ballasts values of masses, springs and dampers were calculated as proposed by Sun \& Dhanasekar [26] on the basis of the experimental results showed in section 2.3.1 and 2.3.2.

Instead for the over-compacted layer the same values were obtained on the basis of a dynamic modulus equal to 5,000 $\mathrm{MPa}$.
On the basis of the elastic modulus equal to $20 \mathrm{MPa}$ the stiffness of the subgrade was calculated as proposed by Lei and Rose [27].

It was considered the ALn 668 train in single configuration moving at a speed of $90 \mathrm{~km} / \mathrm{h}$ which has the characteristics above mentioned (Table 5). The load frequency on the sub-ballast, according to the data (in particular the speed), is equal around to $2 \mathrm{~Hz}$. The vertical irregularities of the track were calculated using the PSD (power spectral density) proposed by the America Railway Standard for class 6 lines [23].

\section{Results}

The highest deflections of each component at the several temperatures are reported in the Figs. 10a-10c. Within the range temperature both the ballasted rail tracks practically showed the same deflections. It can be noted that the lower stiffness of the DARC1.5 sub-ballast does not produce a growth of the deformation because the viscous properties increased and opposed the deformation at the considered load frequency. 
Table 4 Track parameters.

\begin{tabular}{llllll}
\hline Track components & $\begin{array}{l}\text { Mass per unit length Damping } \\
(\mathrm{kg} / \mathrm{m})\end{array}$ & $\begin{array}{l}\text { Mass } \\
\text { ratio }\end{array}$ & $\begin{array}{l}\text { Stiffness } \\
(\mathrm{kg}) / \mathrm{m})\end{array}$ & $\begin{array}{l}\text { Damping } \\
(\mathrm{Kn} / \mathrm{m})\end{array}$ \\
\hline Rail & $m_{r}: 60$ & $\xi_{r}: 0.02$ & - & - & - \\
Sleeper & - & - & $M_{s}: 260$ & - & - \\
Fastenings system & - & - & - & $K_{p}: 60$ & $C_{p}: 77.76$ \\
Ballast & - & - & $M_{b}: 270$ & $K_{b}: 158.11$ & $C_{b}: 41.30$ \\
Asphalt sub-ballast & $m_{s b}:$ variable & $\xi_{s b}:$ variable & - & $K_{w}: 78.40$ & $C_{w}: 80.00$ \\
$\begin{array}{l}\text { Over-compacted } \\
\text { layer }\end{array}$ & - & - & $M_{s c}: 2,300$ & $K_{s b}:$ variable & $C_{s b}:$ variable \\
Subgrade & - & - & - & $K_{s c}: 2,066.63$ & $C_{s c}: 21.830$ \\
\hline
\end{tabular}
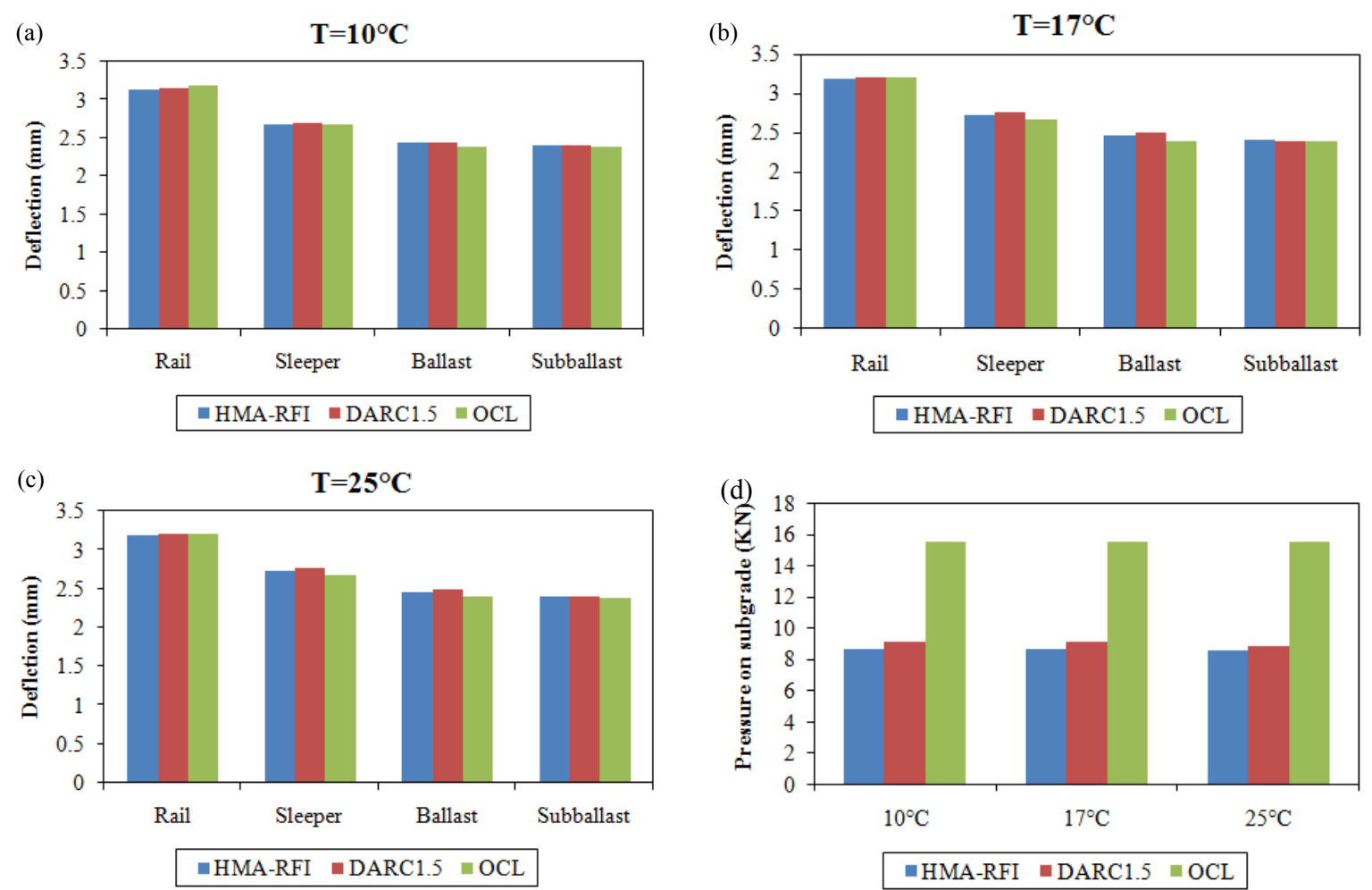

Fig. 10 Deflection of the track: (a) $10^{\circ} \mathrm{C}$; (b) $17^{\circ} \mathrm{C}$; (c) $25^{\circ} \mathrm{C}$; (d) Dynamic force on the top of subgrade.

\section{Table 5 Characteristics of ALn 668 Train.}

\begin{tabular}{ll}
\hline ALn 668 vehicle & \\
\hline Total mass $\left(\mathrm{k}_{\mathrm{g}}\right)$ & 28,800 \\
Bogie mass $\left(\mathrm{k}_{\mathrm{g}}\right)$ & 3,600 \\
Wheelset mass $\left(\mathrm{k}_{\mathrm{g}}\right)$ & 500 \\
Total length $(\mathrm{mm})$ & 23,540 \\
Wheel distance $(\mathrm{mm})$ & 2,450 \\
Bogie distance $(\mathrm{mm})$ & 15,950 \\
Primary suspension stiffness $(\mathrm{kN} / \mathrm{m})$ & $5 \times 10^{5}$ \\
Secondary suspension stiffness $(\mathrm{kN} / \mathrm{m})$ & $8.8 \times 10^{5}$ \\
Primary suspension damping $(\mathrm{N} \mathrm{s} / \mathrm{m})$ & 500 \\
Secondary suspension damping $(\mathrm{N} \mathrm{s} / \mathrm{m})$ & 41,500 \\
\hline
\end{tabular}

In the Fig. 10d the maximum dynamic pressures (i.e., forces on sleeper spacing) on the top of the subgrade are depicted, they represent the main source of the ground borne vibrations.

Furthermore, the maximum dynamic pressures of the rail track model with sub-ballast were around $40 \%$ lower than the rail track that with OCL (over-compacted layer), even though the maximum dynamic deflections of the two different models are very close. 
Hence, it can be found that the ballasted rail track with HMA-RFI sub-ballast layer has a higher bearing capacity than rail track with DARC1.5 sub-ballast.

However, both the ballasted rail track with asphalt sub-ballast seemed to have a higher bearing capacity than rail track with over compacted layer.

\section{Conclusions}

In this paper, the opportunity of the use of DARC (dry asphalt rubber concrete) in railways application has been evaluated.

Within this study, laboratory tests were conducted (4BP-PR and Marshall tests) in order to determine the stiffness and the damping ratio of two materials: the first was a bituminous mixture called HMA-RFI, the second was an hot bituminous mixture with a rubber content equal to $1.5 \%$ that was called DARC1.5.

Based on the experimental study, some preliminary conclusions can be drawn:

- Within the frequency range [2, $20 \mathrm{~Hz}]$ which is particularly relevant in railway field, the value of DARC stiffness modulus $\left|E^{*}\right|$ is about an half of the HMA-RFI's for every temperature test;

- The value of the DARC1.5 damping ratio at 17 and $25^{\circ} \mathrm{C}$ was higher (5-27\%) than the HMA-RFI one. The main increases (40-127\%) of the damping ratio were reached at $10^{\circ} \mathrm{C}$.

Hence, the DAR1.5 seems to be suitable for sub-ballast in order to reduce the vibration level.

Then, a numerical analysis was conducted by means of 2D lumped masses model developed by the authors, utilizing the experimental results on the materials.

Based on this numerical analysis the following conclusions can be drawn:

- The lower stiffness of the DARC1.5 sub-ballast does not produce a growth of the deformation because the viscous properties increased and opposed the deformation at the considered load frequency $(2 \mathrm{~Hz})$;

- The maximum dynamic deflections of the two different models are almost equal for the DARC sub-ballast and HMA-RFI sub-ballast;
- In relation to the maximum dynamic pressures the ballasted rail track with HMA-RFI sub-ballast seemed to have higher bearing capacity than rail track with DARC1.5 sub-ballast.

Thus, the DARC seems to be a good material for railway applications above all in order to control the ground born vibrations produced by train. In addition, this material allows to reclaim big quantities of rubber from the waste tires and so it can be considered as a green technology.

\section{References}

[1] D. Orlandi, Fatigue of the Bituminous Sub-Ballast Layer, Italian Railway Engineering, June 1984, pp. 317-322. (in Italian)

[2] D. Orlandi, Why a Sub-Ballast, Italian Railway Engineering, Aug. 1985, pp. 447-453. (in Italian)

[3] J. G. Rose, Performance and economics evaluation of hot mix asphalt railway trackbeds, in: Proceedings of the 98th Annual Conference of the Roadmasters and Maintenance of Way Association, Chicago, IL, Sep. 10-11, 1986, pp. 119-113.

[4] G. J. Rose, P. F. Teixeira and N. E. Ridgway, Utilization of asphalt/bituminous layers and coatings in railway trackbeds - A compendium of international applications, in: Proceedings of the 2010 Joint Rail Conference (JCR 2010), Urbana, Illinois, USA, Apr. 27-29, 2010, p. 17.

[5] Y. H. Huang, J. G. Rose and C. J. Khoury, Thickness design for hot-mix asphalt railroad trackbeds, Annual Journal AAPT, Miscellaneous 56 (87) (1987) 427-453.

[6] J. G. Rose, Asphalt trackbeds: Selection, design, installation pratices, long-term performances \& material properties, in: Proceedings of Railway Engineering-2000 of 3rd International Conference and Exhibition, London, July 2000, p. 12.

[7] J. G. Rose, D. Li and L. A. Caldwell, Tests and evaluation of in-service asphalt trackbeds, American Railway Engineering and Maintenance Association, in: Annual Conference Proceedings, Washington D.C., Sep. 2002, p. 16

[8] Y. Momoya and E. Sekine, Performance-based design method for railway asphalt roadbed, Doboku Gakkai Ronbunshuu E 63 (2007) 608-619.

[9] C. Giavarini and C. Ravaioli, The asphalt in the railway field, Bitumen Review 35 (2000) 33-36. (in Italian)

[10] A. Buonanno and R. Mele, The use of bituminous mix sub-ballast in the Italian State Railways, in: 2nd Eurasphalt and Eurobitume Congress, Barcelona, Spain, 2000. 
[11] L. A. Scofield, The History, Development and Performance of Asphalt Rubber at ADOT, Report AZ-SP-8902, Arizona Transportation Research Center, Arizona Department of Transportation, 1989.

[12] A. D'Andrea and T. Mariotti, Asphalt mixes containing crumb rubber (1st Part), Bitumen Review 39 (1) (2001) 21-33. (in Italian)

[13] B. Celauro, C. Celauro and A. Di Francisca, Experimental survey on CRM (crumb rubber modifier) within asphalt mixes via dry process, in: XIII National S.I.I.V. Congress, Padua, Italy, Oct. 30-31, 2003. (in Italian)

[14] A. D'Andrea, L. Urbani and G. Bonin, Traffic vibration damping whit innovative materials: Development and calibration of a simulation model, in: 2th International S.I.I.V. Congress, Florence, Italy, Oct. 27-29, 2004.

[15] X. Zeng, J. G. Rose and J. S. Rice, Stiffness and damping ratio of rubber-modified asphalt mixes: Potential vibration attenuation for high-speed railway trackbeds, Journal of Vibration and Control 7 (2001) 527-538.

[16] X. G. Zhong, X. Zeng and J. G. Rose, Shear modulus and damping ratio of rubber-modified asphalt mixes and unsaturated subgrade soils, Journal of Materials in Civil Engineering 14 (6) (2002) 496-502.

[17] C. J. Wang, X. Zeng and R. L. Mullen, Three-dimensional finite element simulations of ground vibration generated by high-speed trains and engineering countermeasures, Journal of Vibration and Control 11 (12) (2005) 1437-1453.

[18] P. Bonafè, Modified bitumen white crumb rubber Asphalt rubber technology, Bitumen Review 58 (8) (2008) 67-70. (in Italian)
[19] UNI, UNI EN 12697-26: Bituminous Mixtures — Test Methods for Hot Mix Asphalt - Part 26: Stiffness, Nov. 2004.

[20] UNI, UNI EN 12697-34: Bituminous Mixtures — Test Methods for Hot Mix Asphalt — Part 34: Marshall Test, July 2007.

[21] M. Crispino, Evaluation of in service temperature within rail sub-ballast, Italian Railway Engineering, Italy, 2001, pp. 30-36. (in Italian)

[22] J. Wang, X. Zeng and D. A. Gasparini, Dynamic response of high-speed rail foundations using linear hysteretic damping and frequency domain substructuring, Soil Dynamics and Earthquake Engineering 28 (2008) 258-276.

[23] X. Lei and N. A. Noda, Analyses of dynamic response of vehicle and track coupling system with random irregularity of track vertical profile, Journal of Sound and Vibration 258 (1) (2002) 147-165.

[24] R. Panagin, The Railway Vehicle Dynamics, Leprotto \& Bella, Turin, 1990. (in Italian)

[25] J. B. Roberts and P. D. Spanos, Random Vibration and Statistical Linearization, John Wiley \& Sons Ltd, New York, 1990.

[26] Y. Q. Sun and M. Dhanasekar, A dynamic model for the vertical interaction of the rail track and wagon system, International Journal of Solids and Structures 39 (2002) 1337-1359.

[27] X. Lei and J. G. Rose, Numerical investigation of vibration reduction of ballast track with asphalt trackbed over soft subgrade, Journal of Vibration and Control 14 (12) (2008) 1885-1902. 